\title{
Central Roles of the Roof Plate in Telencephalic Development and Holoprosencephaly
}

\author{
Xun Cheng, ${ }^{1}$ Ching-mei Hsu, ${ }^{1}$ D. Spencer Currle, ${ }^{1,2}$ Jia Sheng Hu, ${ }^{1,2}$ A. James Barkovich, ${ }^{3}$ and Edwin S. Monuki ${ }^{1,2}$ \\ ${ }^{1}$ Department of Pathology and Laboratory Medicine, University of California Irvine School of Medicine and ${ }^{2}$ Department of Developmental and Cell \\ Biology, University of California Irvine School of Biological Sciences, Irvine, California 92697, and 3Departments of Radiology, Neurology, Pediatrics, and \\ Neurosurgery, University of California San Francisco School of Medicine, San Francisco, California 94143
}

The roof plate is a well known signaling center in CNS development, but its roles in the developing telencephalon and the common holoprosencephaly (HPE) malformation have been uncertain. Using cellular ablations in mice, we show that roof plate cell loss causes failed midline induction and HPE in the dorsal telencephalon. This morphologic phenotype is accompanied by selective deficits in midline gene expression and a reduced activity gradient for bone morphogenetic proteins (Bmps), the major signals produced by the roof plate. In dissociated cells and mutant explants, exogenous Bmp4 is sufficient to mimic roof plate selectivity in midline gene regulation and to rescue roof plate-dependent midline patterning. Previously unrecognized neuroanatomical defects predicted by the mouse model are then confirmed in human HPE patients. These findings establish selective roles for roof plate-dependent Bmp signaling in dorsal telencephalic patterning and HPE and define novel candidate genes for the human disorder.

Key words: cerebral cortex; choroid plexus; cortical hem; transgenic mice; neural stem cell; neuropathology; middle interhemispheric variant; Zic2; Lhx5

\section{Introduction}

Despite its fame, the roof plate (RP) has been an elusive target in the developing forebrain. The RP, which forms at the dorsal midline of the neural tube, is crucial for dorsal patterning of the spinal cord (Liem et al., 1997; Lee and Jessell, 1999) and hindbrain (Millonig et al., 2000; Chizhikov et al., 2006). In the cord, RPdependent patterning is primarily mediated by secreted bone morphogenetic proteins (Bmps) (Liem et al., 1997; Lee and Jessell, 1999), and multiple Bmps are expressed in the forebrain RP (Furuta et al., 1997). However, forebrain RP functions have defied elucidation because of early lethality, functional redundancy, and lack of RP-specific expression among Bmps and their antagonists (Solloway and Robertson, 1999; Bachiller et al., 2000; Anderson et al., 2002; Hebert et al., 2003; Zhao, 2003). In addition, our previous RP ablations using Gdf7 [growth differentiation factor 7 (Bmp12)] transgenic mice were confounded by severe open forebrain defects (Monuki et al., 2001).

Establishing RP involvement in holoprosencephaly (HPE), the most common congenital malformation of the human forebrain ( 1 in 10,000 live births, 1 in 250 conceptions), has also been difficult. HPE results from defective midline induction and subsequent failure to separate the cerebral cortex and other bilateral

Received 0ct. 5, 2005; revised June 8, 2006; accepted June 8, 2006.

This work was supported by National Institutes of Health Grant K02 NS053511, the March of Dimes Birth Defects Foundation, and the Whitehall Foundation (E.S.M.). We thank those who provided CDNA reagents, Kevin Lee and Tom Jessell for mice, Ken Zaret for advice on explant cultures, and Lisa Flanagan, Greg Lemke, and Chris Walsh for manuscript comments.

Correspondence should be addressed to Edwin S. Monuki, University of California, Irvine, D440 Medical Sciences I, Irvine, CA 92697-4800. E-mail: emonuki@uci.edu.

DOI:10.1523/JNEUROSCI.0714-06.2006

Copyright $\odot 2006$ Society for Neuroscience $\quad$ 0270-6474/06/267640-10\$15.00/0 forebrain structures. RP involvement is suggested by the high prevalence of dorsal cortical pathology in "classical" HPE (Monuki and Walsh, 2001; Hayhurst and McConnell, 2003) and the dorsally restricted cortical phenotype in the middle interhemispheric (MIH) HPE variant (Barkovich and Quint, 1993; Simon et al., 2002). Among human genes, only ZIC2 (zinc finger protein of cerebellum 2) has been specifically linked to the MIH subtype (Brown et al., 2001; Marcorelles et al., 2002), and Zic2 knockdown in mice causes failed RP induction (Nagai et al., 2000). However, Zic2 is expressed both dorsally and ventrally (see Fig. 2E) (Nagai et al., 1997; Hayhurst and McConnell, 2003), thus lacking RP specificity, and most ZIC2 mutations cause classical HPE involving the ventral forebrain (Brown et al., 2001). Likewise, HPE induction resulting from excessive Bmp signaling (Golden et al., 1999; Bachiller et al., 2000; Anderson et al., 2002; Ohkubo et al., 2002) has been attributed to a ventral rather than dorsal defect, namely, suppression of ventral Sonic hedgehog (Shh) production, a well known cause of classical HPE in mice and humans (Muenke and Beachy, 2000).

To address the RP selectively, we previously modified the Gdf7-mediated ablation strategy to generate mouse embryos with a closed forebrain phenotype (see Fig. 1A) (Currle et al., 2005). This allowed us to define a primarily cell-nonautonomous requirement for RP cells in telencephalic choroid plexus epithelium ( $\mathrm{tCPe}$ ) induction. In this report, we use the improved ablations to establish a primary role for the RP in MIH HPE induction. Culture studies include rescue experiments that indicate the sufficiency of Bmp4 to reverse HPE-associated defects and mimic $\mathrm{RP}$-dependent midline patterning. We then extend these observations to identify previously unrecognized neuroanatomical de- 
fects in human MIH HPE patients that are directly predicted by the mouse RP ablation phenotype.

\section{Materials and Methods}

Mice. Noon of the vaginal plug date was day 0.5 in timed pregnancies between ACTB-Cre ( $\beta$-actin-Cre recombinase) (stock 003376; The Jackson Laboratory, Bar Harbor, ME) and Gdf7-DTA (Gdf7-diphtheria toxin) (Lee et al., 2000a) mice. Gdf7-DTA mice on native (mostly C57BL/6) or CD1 outbred background (five to six generations) yielded indistinguishable mutant phenotypes (see Fig. $1 \mathrm{~A}$, B6 background in top row and CD1 background in bottom row). CD1 or C57BL/6 (B6) mice (Charles River Laboratories, Wilmington, MA) were used for wild-type studies. Genotypes were determined by gross morphology and/or PCR genotyping (Monuki et al., 2001). Mutants with open forebrain defects were excluded from additional analysis. All animal studies were performed in accordance with Institutional Animal Care and Use Committee guidelines.

In situ hybridization, immunohistochemistry, and histology. These were performed and imaged as described previously (Monuki et al., 2001; Currle et al., 2005) using the following probes: Emx2 [empty spiracles homolog 2; Eduardo Boncinelli (University Vita-Salute, Milan, Italy), David Rowitch, and Keith Ligon (both from Dana Farber Cancer Institute, Boston, MA)], Fgf8 [Ivor Mason (King's College London, London, UK), Anne Calof, and Shimako Kawauchi (both from University of California, Irvine)], Foxg1 [forkhead box G1; IMAGE (Integrated Molecular Analysis of Genomes and their Expression Database) clone 388688], Lhx2 (Richard Maurer, Oregon Health \& Science University, Portland, OR), Lhx5 (LIM homeobox 5; Stefano Bertuzzi, National Institutes of Health, Bethesda, MD), Lmxla (LIM homeobox transcription factor $1 \alpha$; Kathy Millen and Victor Chizhikov, University of Chicago, Chicago, IL), Ngn2 (neurogenin 2; Quifu Ma, Dana Farber Cancer Institute), Pax6 (paired box gene 6; IMAGE clone 4504106), Tgif (TGFB-induced factor; IMAGE clone 3595273), Shh (Chris Walsh and Jun Shen, Beth Israel Deaconess Medical Center, Boston, MA), Six3 (sine oculis homeobox homolog 3; Guillermo Oliver, St. Jude Children's Research Hospital, Memphis, TN), Tbr1 [T-box brain 1; John Rubenstein (University of California, San Francisco, CA) and Robert Hevner (University of Washington, Seattle, WA)], Ttr (transthyretin; IMAGE clone 1078224), Wnt2b (wingless/int family, member 2b; IMAGE clone 353765), Wnt3a (IMAGE clone 426103), Wnt5a (IMAGE clone 775462), and Zic2 [BMAP (Brain Molecular Anatomy Project Database) clone U1-M-BH1alr-f-09-0-UI]. The following antibodies were used: LH2 (LIM/homeodomain protein 2; rabbit polyclonal against chick LH2A/B, recognizes mouse Lhx2/9; 1:250 dilution; Gabi Tremml and Tom Jessell, Columbia University, New York, NY), TuJ1 (rabbit polyclonal against rat peptide, recognizes same class III $\beta$-tubulin epitope as clone TUJ1; 1:2500 dilution; catalog \#RDI-tubulBlabR; Research Diagnostics, Flanders, NJ), and pSmad1/5/8 (phosphorylated Smad, mothers against DPP homolog 1, 5, and 8) (rabbit polyclonal against human Smad5 phosphopeptide, recognizes double phosphorylated Smad1, Smad5, and Smad8; 1:40 dilution; catalog \#AB3848; Chemicon, Temecula, CA). Although the LH2 antibody recognizes both Lhx2 and Lhx9, only Lhx2 is detectable in the cortical ventricular zone at the stages immunostained in this study (Monuki et al., 2001). Mutant sections adjacent to those with little to no ISH signal (see Fig. 2) were confirmed to have well preserved mRNA in other ISH studies. For all comparative images and intensity measurements, tissue processing, assays, image acquisition, processing, and enhancements were performed in parallel on sections from comparable rostrocaudal levels. Unless otherwise indicated, presented images are representative of multiple sections from a minimum of two embryos.

Cortical ISH (see Fig. 3B) and pSmad gradients (see Fig. 4C) were measured in NIH ImageJ using the segment line tool drawn through the middle of the neuroepithelium (i.e., halfway between ventricular and pial surfaces). The dorsal midline region (choroid plexus and cortical hem) was avoided in cortical ISH measurements, pSmad measurements began at the immediate midline, and segmented lines ended just proximal to the corticostriatal border. The average pSmad gradient (see Fig. $4 C$ ) was derived from 22 mutant and 18 control hemispheres (three embryos, three to four sections, both hemispheres). Based on correlation coeffi- cients, curve fits were generally best using second-order polynomials rather than linear or exponential equations; however, to simplify visual comparison, linear curve fits are shown in Figure 3. M phase cell intensities (see Fig. $4 D$ ) were calculated from randomly selected individual cells measured in NIH ImageJ using the polygon tool; "medial" cells were from the one-third of neuroepithelium closest to the dorsal midline, whereas "lateral" cells were from the one-third closest to the corticostriatal border. Although the ventricular surface is prone to edge staining artifact, the following evidence suggests specific pSmad immunoreactivity in M phase cells: (1) labeling of many, but not all, cells at the ventricular surface at embryonic day 10.5 (E10.5) and E12.5; (2) significantly reduced $\mathrm{M}$ phase cell immunoreactivity in RP ablated mutants at E10.5 and E12.5; (3) similar patterns of $\mathrm{M}$ phase cell immunoreactivity in cultured cells treated with and without Bmp4; (4) the predicted nuclear specificity during interphase; (5) the absence of signal in standard negative controls (omission of primary pSmad antibody) included on every slide; and (6) the selective lack of M phase cell staining by other rabbit polyclonal antibodies used in the laboratory. All $p$ values were calculated using two sample, two-tailed $t$ tests.

Real-time semiquantitative reverse transcription-PCR. RNA preps, cDNA syntheses, PCR quality controls, experimental runs, and statistical methods were performed as described previously (Currle et al., 2005). All primers and amplicons (supplemental Table 1, available at www. jneurosci.org as supplemental material) were verified by amplification efficiency testing, melting curve analysis, and agarose gel electrophoresis; all experimental amplicons were also verified by sequencing. All cDNA samples were validated for reverse transcription (RT) reaction efficiency and minimal genomic DNA contamination (cDNA/genomic target ratio $>10^{5}$ ) and run in duplicate or triplicate for 40 cycles; cyclophilin A (CYPA) and $18 \mathrm{~S}$ reference primers were included in all experimental runs, except for the explant studies (CYPA only). Mean, SEM, SD, and $p$ values (two sample, two-tailed $t$ tests) were calculated from $\Delta \mathrm{Ct}$ (cycle threshold) values $\left(\mathrm{Ct}_{\text {gene of interest }}-\mathrm{Ct}_{\text {reference }}\right)$ and plotted as normalized $-\Delta \mathrm{Ct}$ values (normalized to 0 and plotted such that upregulation is positive and downregulation is negative) to accurately account for control sample variation, which is inaccurate for $\Delta \Delta \mathrm{Ct}$ and $2^{-\Delta \Delta \mathrm{Ct}}$ values (control samples normalized to either 0 or 1 before statistics). For conversion of plotted data to relative levels, relative levels = $2^{\text {(normalized }-\Delta \mathrm{Ct})}$. CYPA-normalized data are presented; 18S-normalized data are provided in supplemental Figure 2 (available at www.jneurosci. org as supplemental material). Sample numbers are as follows: (1) embryo data (see Figs. 2, 3) (supplemental Fig. 2, available at www. jneurosci.org as supplemental material), three mutant and three to five control littermates from E12.5; (2) explant data (see Fig. 5A) (supplemental Fig. 2, available at www.jneurosci.org as supplemental material), five BSA-treated and five BMP4-treated mutant E10.5 explants cultured for $3 \mathrm{~d}$; (3) dissociated culture data (see Fig. 5C) (supplemental Fig. 2, available at www.jneurosci.org as supplemental material), three independent sets of E12.5 CD1 cultures and two independent sets of E12.5 B6 cultures. No samples were omitted from the presented data. Dorsal forebrain tissue collected for semiquantitative RT (qRT)-PCR did not encompass the rostral and ventral midlines; thus, Shh and Fgf8 qRT-PCR quantifications were not performed. Pax6 levels were not quantified because of poor primer efficiencies.

Dissociated and explant cultures. E12.5 B6 and CD1 dorsal telencephalon were acutely dissociated and cultured in defined media on laminin, as described previously (Flanagan et al., 2006). Base media for B6 (Flanagan et al., 2006) and CD1 cultures (Qian et al., 1998) did not include other growth factors. After adhering overnight, human recombinant BMP4 (R \& D Systems, Minneapolis, MN) at the indicated concentrations was added on 2 consecutive days; RNA was harvested $48 \mathrm{~h}$ after initial BMP4 treatment. ACTB-Cre;Gdf7-DTA explant preparation and culture were modified from previous descriptions (Burrows et al., 1997; Furuta et al., 1997; Monuki et al., 2001). Dissections were performed in ice-cold L-15 supplemented with $2 \%$ glucose. Whole dorsal forebrains with intact overlying ectoderm were placed ventricular surface down on the dull surface of $8 \mu \mathrm{m}$ pore polycarbonate Whatman (Clifton, NJ) membranes floating in a modified media (DMEM/F-12/20\% calf serum supplemented with sodium pyruvate, nonessential amino acids, and 
penicillin-streptomycin). After $1 \mathrm{~h}$ incubation, BMP4 was added to a concentration of $50 \mathrm{ng} / \mathrm{ml}$ on 3 consecutive days. Explants were processed for ISH or RNA extraction $72 \mathrm{~h}$ after initial BMP4 treatment.

Magnetic resonance imaging studies. At least one axial sequence and one coronal (11 patients) and/or one sagittal sequence (20 patients) were available for $23 \mathrm{MIH}$ HPE patients acquired over a period of 19 years. The scans were performed at multiple institutions using a number of different imaging protocols; contrast-enhanced studies were available in only two patients. Each study was evaluated to verify the preferential lack of middle interhemispheric separation, to assess ventricular morphology, to determine the presence and (if present) extent of choroid plexus, and to determine the morphology (normal or abnormal) and size (large, normal, or small) of the hippocampi. The lack of three-dimensional acquisition or original digital data, coupled with the generally poor spatial resolution of secondhand printed or digitized films, precluded meaningful quantification of the neuroanatomic defects.

\section{Results}

\section{RP ablation causes MIH HPE}

For simplicity, we generally use dorsal (i.e., toward the RP) and ventral (away from the $\mathrm{RP}$ ) to describe spatial position and refer to the tCPe and cortical hem as "midline" structures. Our previously reported ablation studies (Currle et al., 2005) are summarized in supplemental Figure 1 (available at www.jneurosci.org as supplemental material). In ACTBCre;Gdf7DTA embryos, excessive cell death occurs transiently in the RP before differentiation of the $\mathrm{tCPe}$ and cortical hem, which results in the reduction of $\mathrm{Bmp}$ mRNA levels (Bmp4, Bmp6, and Bmp7). Although RP cell lineages do not contribute to most of the tCPe (or cortical hem), RP cell ablation results in near-total tCPe absence, thus indicating a major cell-nonautonomous requirement for RP cells in tCPe induction (Currle et al., 2005).

Consistent with the absence of tCPe, RP ablation also resulted in failed separation of the cortical primordia at the dorsal midline (Fig. $1 A, B$ ). Interestingly, this failure was regionally restricted to middle interhemispheric regions (i.e., telencephalic vesicles were normally separated anteriorly and posteriorly) in all mutant embryos examined by serial section analysis (Fig. $1 B$ ) $(n=14)$. The lack of middle interhemispheric separation was evident at the histologic and molecular levels in both the precursor (ventricular zone) and mantle layers (Fig. 1C,D). Mutants often retained partial midline character (e.g., thinner epithelium, partial Foxg1 and Lhx2 suppression, and
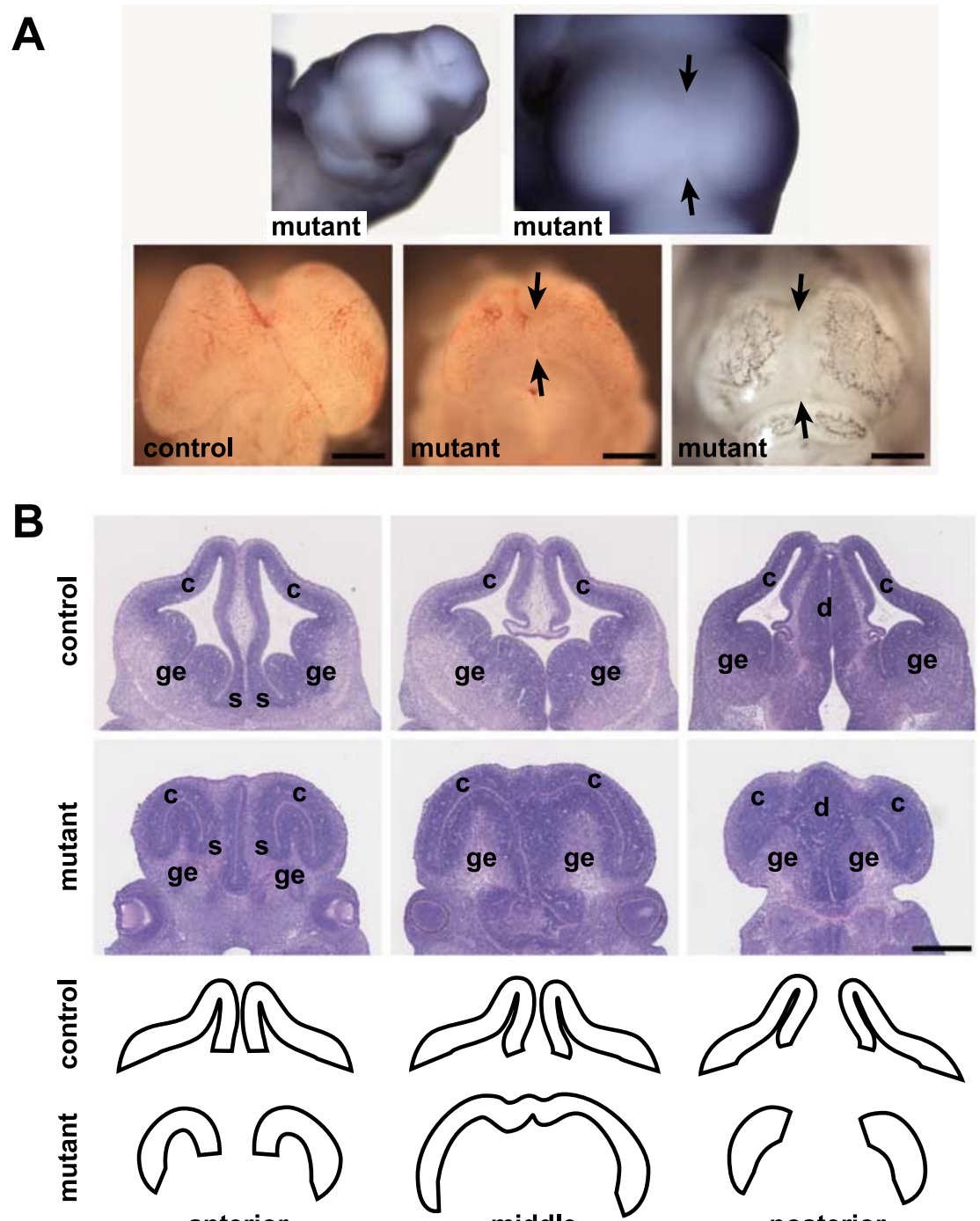

anterior

middle

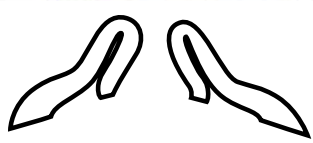

C
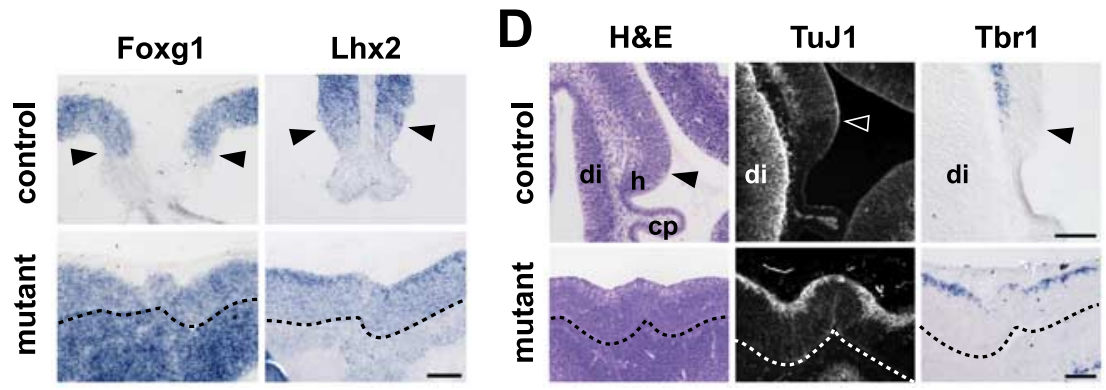

Figure 1. RP ablation induces MIH HPE. A, E12.5 fixed embryo (top row) and freshly dissected CNS tissue (bottom row, except for the far right, which was fixed and stained with dilute ink for improved contrast); forebrain close-ups are dorsal views (top is anterior). RP ablated embryos display poor midline development and incomplete separation in the middle interhemispheric region (between arrows), whereas anterior and posterior regions remain separated bilaterally. An open neural tube is present caudally. The eyes and midline craniofacial region lack obvious defects. Scale bars, $0.5 \mathrm{~mm}$. B, E12.5 coronal hematoxylin and eosin (H\&E) stains and corresponding cortical outlines. Cortical primordia fail to separate in mutants but only at middle interhemispheric levels. The ventricles also collapse after ablation, a feature seen in some human MIH and classical HPE cases. Scale bar, $0.4 \mathrm{~mm}$. C, D, Midline ventricular zone and mantle layer. Foxg1 and Lhx2 are normally absent from the E11.5 midline, but their expression becomes continuous across the midline in mutants. E12.5 mutants also possess telencephalic neurons (TuJ ${ }^{+} /$ $\mathrm{Tbr}^{+}$) that are normally absent from the midline mantle layer. Scale bars, $0.1 \mathrm{~mm}$. Dashed lines demarcate the ventricular surface in mutants; arrowheads designate the cortex-hem boundary. Top is dorsal for all section images. c, Cortex; $c p, c h o r o i d$ plexus; $d$ or di, diencephalon; ge, ganglionic eminence; $h$, hem; s, septum. 
A

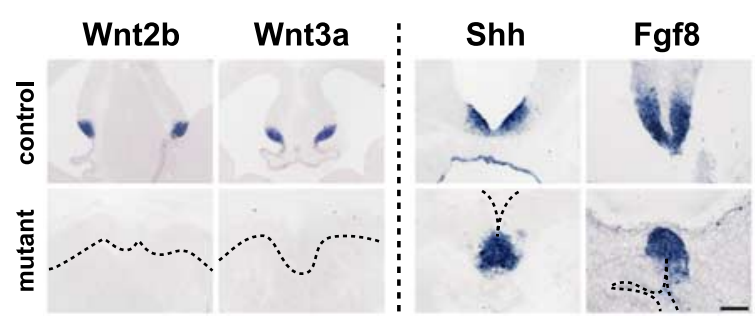

C
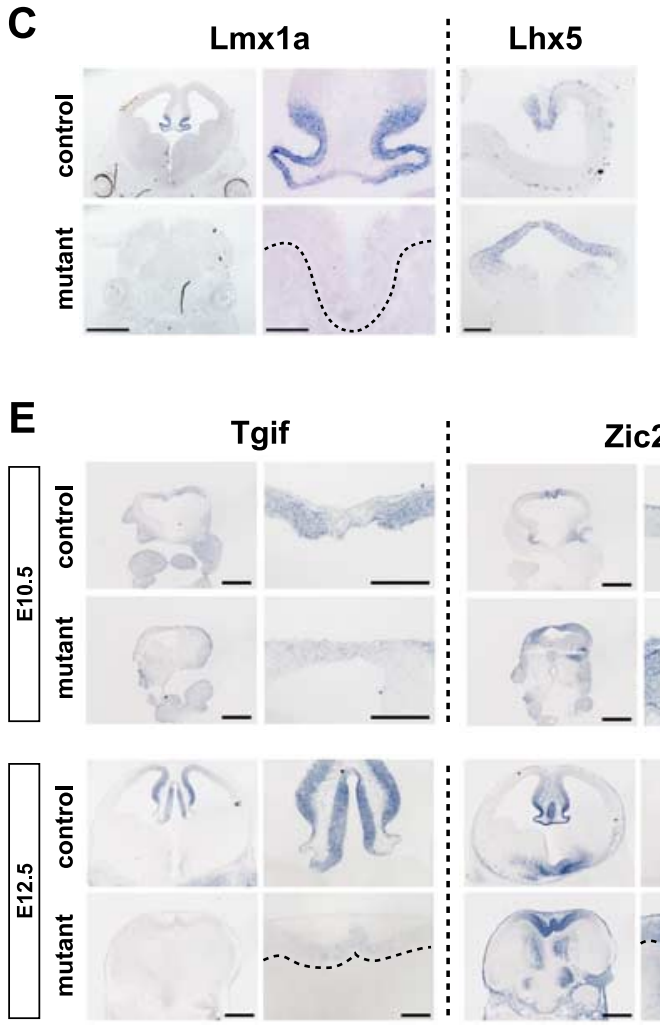

Figure 2. Selective defects in midline gene expression after RP ablation. ISH and qRT-PCR analyses. All images are coronal (top is dorsal), except for Fgf8 (horizontal/axial; top is anterior). $\boldsymbol{A}, \boldsymbol{B}$, Midline signals. Wnt2b and Wnt3a, which are selectively expressed in the normal E12.5 cortical hem, are markedly reduced in mutants. Ventral Shh and rostral Fgf8 are well preserved. The Fgf8-expressing rostral midline is everted as a result of marked telencephalic hypoplasia. Scale bar, $0.2 \mathrm{~mm}$. cl, Control; mt, mutant. $\boldsymbol{C}, \boldsymbol{D}$, Midline LIM homeobox genes. Lmx1a is selectively expressed in the tCPe and cortical hem at E12.5 and is markedly reduced in mutants. In contrast, Lhx5 expression is maintained and its domain expanded in E10.5 mutants (C), and Lhx5 transcripts are significantly increased in E12.5 mutants relative to controls $(\boldsymbol{D})$. Scale bars: low power Lmx1a, $0.5 \mathrm{~mm}$; all others, 0.1 $\mathrm{mm} . \boldsymbol{E}, \boldsymbol{F}, \mathrm{HPE}$ genes. Tgif is preferentially expressed in cortical neuroepithelia, whereas Zic2 expression is highest in the RP. After RP ablation, Tgiflevels are significantly reduced, whereas Zic2 expression is maintained or slightly increased. Like that of Lhx5, the expression domain of Zic2 appears expanded in mutants. Dashed lines demarcate the ventricular surface. Scale bars: low magnifications, $0.5 \mathrm{~mm}$; high magnifications, $0.2 \mathrm{~mm}$. Error bars indicate SEM; ${ }^{* *} p<0.01$.

Tbr1 expression) but uniformly displayed total to near-total absence of tCPe markers and morphology (Currle et al., 2005) as well as hem markers (Fig. 2A-D). RP ablation therefore leads to an MIH HPE phenotype (Barkovich and Quint, 1993; Simon et al., 2002), which is consistent with the Gdf7 genetic fate map and the spatiotemporal pattern of ablation (Currle et al., 2005).

The MIH HPE phenotype was also associated with partial to total ventricular reduction (Fig. $1 B$ ) by E12.5, a feature seen in some MIH (Ming and Golden, 2004) and classical HPE cases in humans (Norman, 1995; Takahashi et al., 2003). Other defects included a small forebrain preferentially affecting the dorsal telencephalon and reduced dorsal diencephalon volume consistent with diencephalic RP ablation (Currle et al., 2005). Although distorted secondarily by the
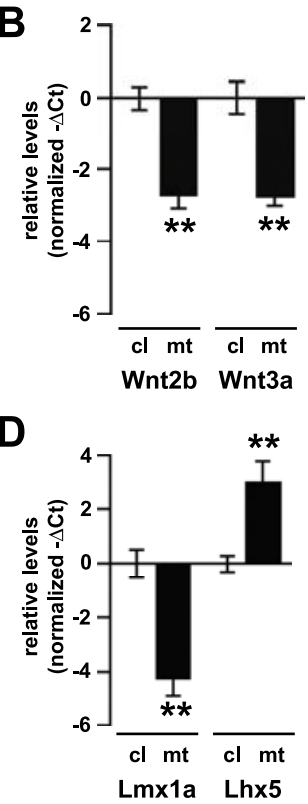

malformed dorsal telencephalon and ventricles, the ventral forebrain did not exhibit midline fusion or other definitive defects, particularly in earlier stage embryos without collapsed ventricles (Fig. 2) (see Fig. 4). The relative lack of craniofacial and ventral forebrain anomalies also distinguishes human MIH HPE from classical forms (Barkovich and Quint, 1993; Simon et al., 2002).

\section{RP ablation causes selective expression deficits in midline genes}

To evaluate the cortical hem, we examined the expression of hem-restricted Wnt2b and Wnt3a (Grove et al., 1998) after RP ablation. Both Wnts were undetectable in E12.5 mutant embryos by ISH (Fig. 2A) and were significantly reduced by $\mathrm{qRT}$ PCR (Fig. 2B). Similar reductions were seen at E13.5 (data not shown), whereas ventral Shh and rostral Fgf8 expression were well preserved in sections and wholemount embryos (Fig. 2A) (data not shown). The maintained Shh and Fgf8 expression was consistent with the absence of Gdf7 cell lineages (in Gdf7Cre;R26R embryos) or excessive cell death (in ACTBCre;Gdf7DTA embryos) in the ventral Shh and rostral Fgf8 expression domains (Currle et al., 2005).

To further evaluate the cortical hem, we examined the LIM homeobox genes Lmxla (Millonig et al., 2000) and Lhx5 (Zhao et al., 1999). Lmxla, which is selectively expressed in the normal hem and tCPe, was markedly reduced by ISH and qRT-PCR after RP ablation (Fig. 2C,D). In contrast, midline Lhx5 expression was not reduced after RP ablation but was instead spatially expanded at E10.5 (Fig. 2C) and increased in overall levels by E12.5 (Fig. $2 D)$. These expression studies indicate that Wnt2b, Wnt3a and Lmxla expression (and the induction of normal cortical hem fate) are dependent on an intact RP, whereas Lhx5 expression lacks this dependence.

\section{RP ablation causes selective expression deficits in HPE-associated genes}

To identify potential genetic pathways involved in RP-dependent HPE, we examined the expression of human HPE-associated genes. Tgif and Zic2 (Fig. 2E), but not Shh or Six3 (data not shown), demonstrated dorsal telencephalic expression in normal E10.5 and E12.5 embryos. Both genes were expressed in the midline and cortical primordia, but Zic2 levels were higher at the midline whereas Tgif was preferentially expressed in cortex. After ablation, Tgif expression was significantly reduced at E10.5 and E12.5, whereas Zic2 expression was maintained and perhaps slightly increased (Fig. 2E,F). Like Lhx5 (Fig. 2C), Zic2 expression was seen in a more expansive domain in RP ablated mutants (Fig. 2E), suggesting that the RP is necessary to restrict Lhx 5 and Zic2 expression to the midline. Thus, unlike the other midline 
genes, Lhx5 and Zic2 do not depend on the RP for upregulated or maintained expression.

RP ablation causes selective disruption of cortical transcription factor gradients

In addition to Tgif, we examined essential cortical patterning genes that normally have graded expression relative to the mid- line. As seen previously in RP ablated mutants with open forebrain defects (Monuki et al., 2001), mutant embryos with closed forebrains exhibited reduced Lhx2 levels in dorsal cortex. This resulted in decreased Lhx2 levels overall (as seen by ISH, immunohistochemistry, and qRT-PCR), as well as flattening and subtle inversion of its normal high dorsal-to-low ventral (DV) gradient (Fig. $3 A-C$ ). A similar extent and pattern of reduction was seen

A
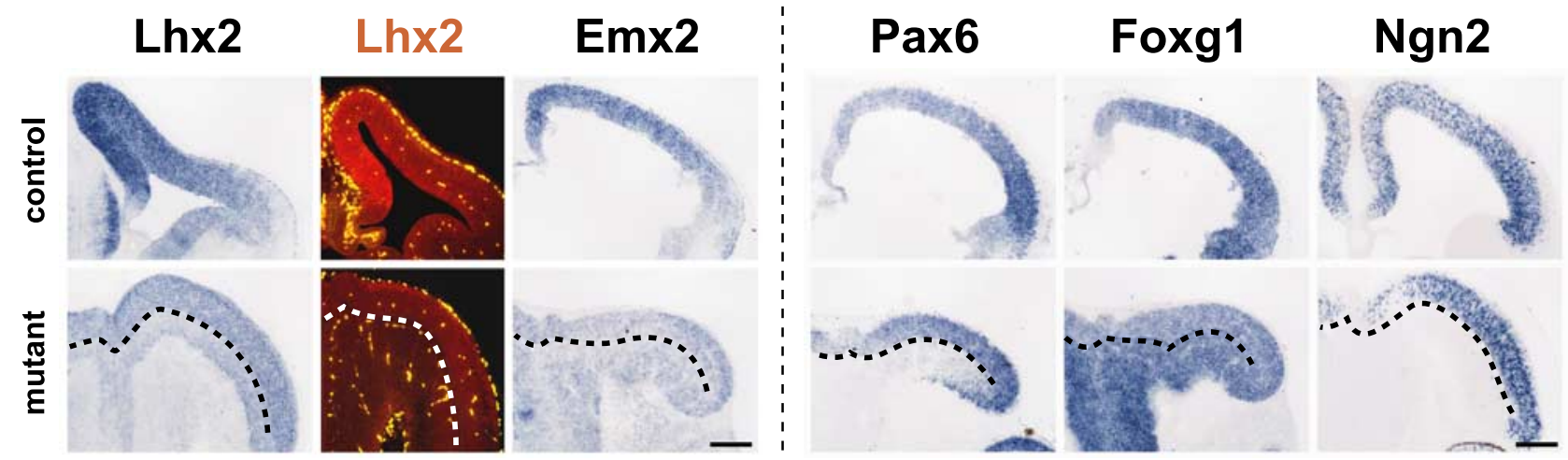

B
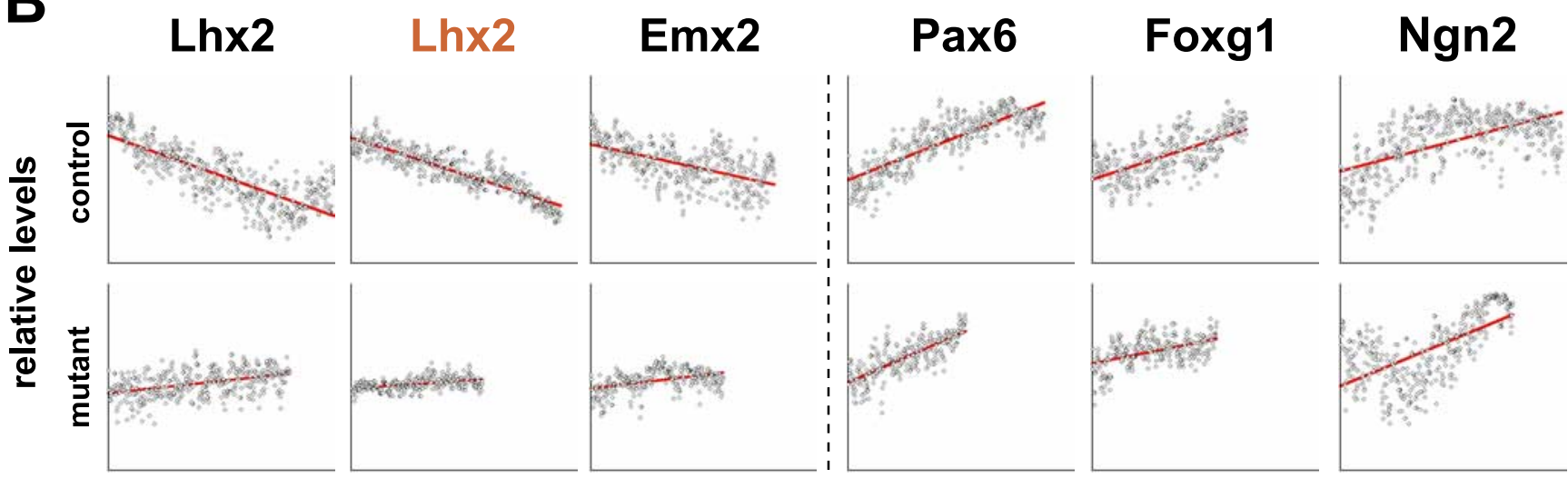

distance from dorsal midline

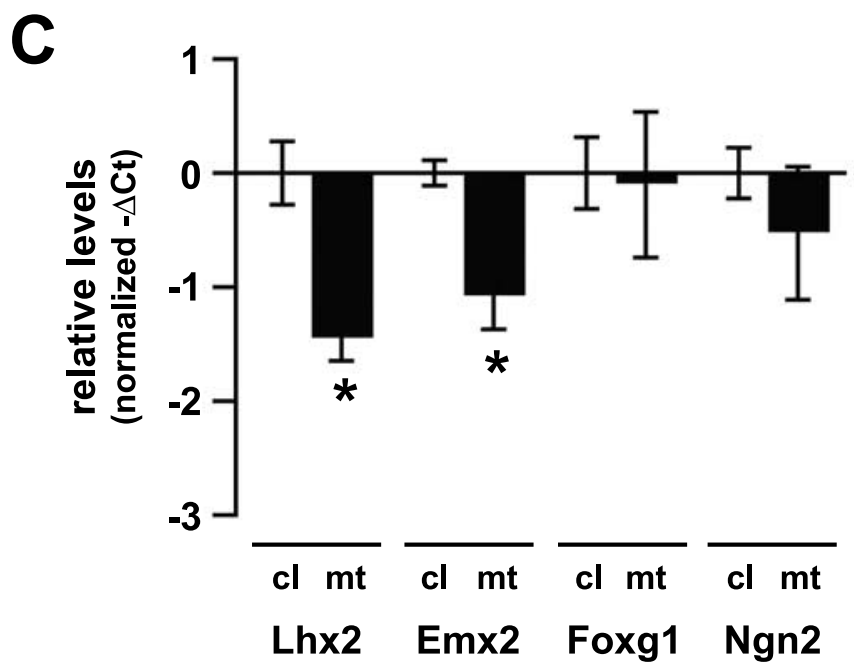

Figure 3. Selective defects in dorsal cortical patterning after RP ablation. $\boldsymbol{A}$, E11.5-E12.5 ISH and Lhx2 immunostaining (red-orange signal; yellow represents autofluorescent red blood cells). Lhx2 and Emx2 levels in mutants are reduced in the dorsal cortical (hippocampal) primordium, resulting in flattened DV expression gradients. In contrast, overall levels and VD gradients of Pax6, Foxg1, and Ngn2 appear unaffected. Dashed lines demarcate the ventricular surface; top is dorsal for all images. Scale bars, $0.2 \mathrm{~mm}$. $\boldsymbol{B}$, ISH signal intensity scatter plots and linear curve fits of images in $\boldsymbol{A}$, plotted on $x$ - and $y$-axes of identical scale. C, qRT-PCR studies confirm the overall reduction in Lhx2 and Emx2 levels in E12.5 mutants (mt) relative to control (cl) littermates, whereas Foxg1 and $\mathrm{Ngn} 2$ expression are maintained. Error bars indicate SEM; ${ }^{*} p<0.05$. 


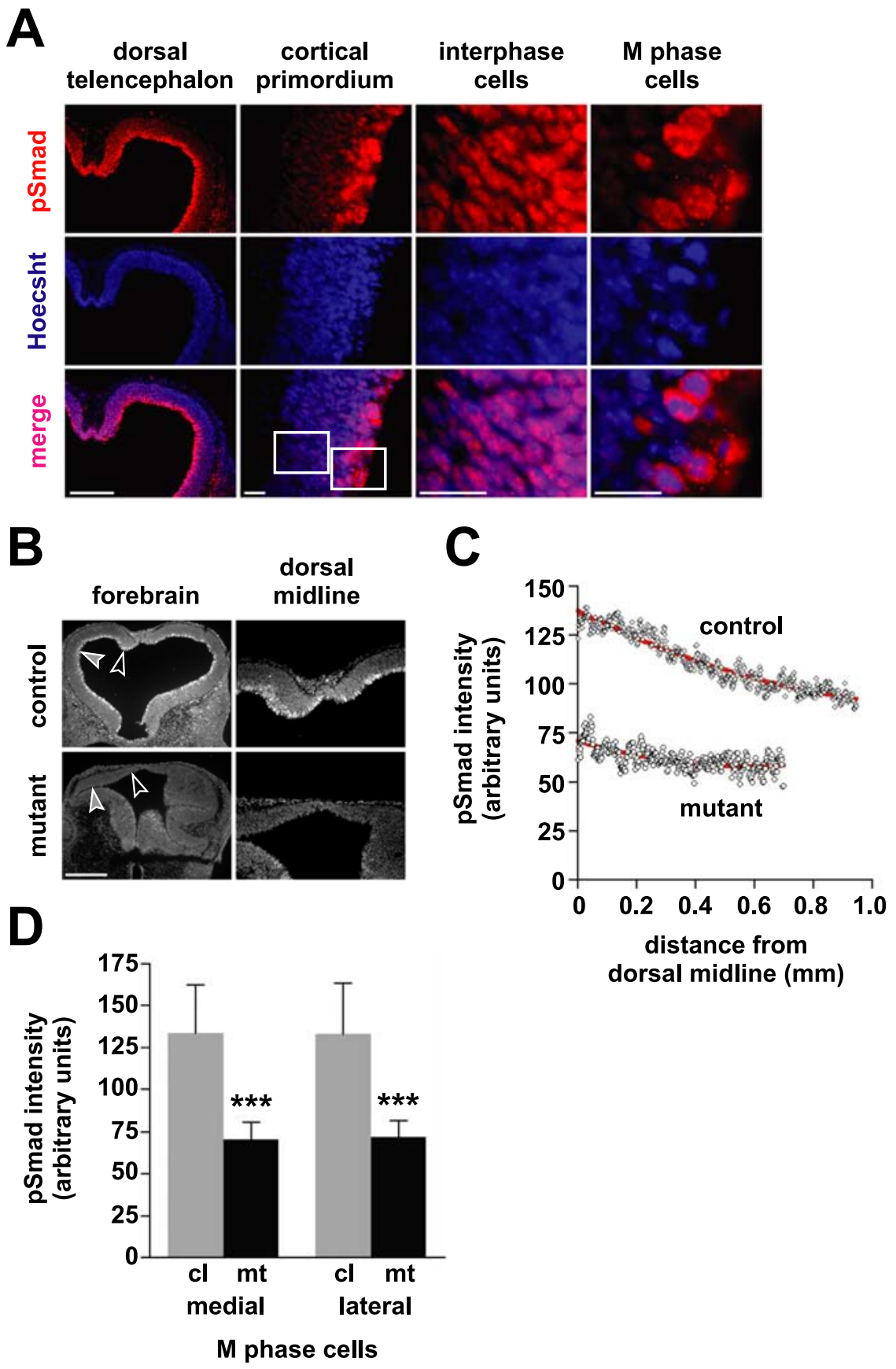

Figure 4. Reduced and flattened Bmp activity gradient after RP ablation. E10.5 pSmad1/5/8 immunohistochemistry with Hoechst nuclear counterstaining. $\boldsymbol{A}$, Normal embryos; boxed regions magnified to the right (M phase images are from a different focal plane). Immunoreactivity for nuclear pSmad displays a DV gradient within interphase regions of the E10.5 dorsal telencephalic ventricular zone and is particularly intense in M phase cells at the ventricular surface. Scale bars: dorsal telencephalon, 0.2 $\mathrm{mm}$; all others, $20 \mu \mathrm{m} . \boldsymbol{B}, \mathrm{RP}$ ablated embryos and controls; black and gray arrowheads designate medial and lateral thirds of the dorsal telencephalon, respectively, which were used in $\boldsymbol{D}$. Overall pSmad immunoreactivity in interphase and $M$ phase cells is reduced in the mutant dorsal telencephalon. Scale bar, $0.2 \mathrm{~mm}$. C, Interphase cell intensity; scatter plots of average pSmad signal with second-order polynomial curve fits. Overall levels of pSmad are reduced and its DV gradient is flattened after RP ablation. Note the correlations with cortical DV gradient profiles in Figure 3. D, M phase cell intensity. Signal intensity is markedly reduced in mutants ( $\mathrm{mt}$ ) relative to controls (cl). Unlike interphase cells, no spatial gradient is detected in M phase cell intensity. Error bars indicate SD; ${ }^{* * *} p<0.0001$.

for Emx2, another DV graded gene. In contrast, three transcription factors normally expressed in high ventral-to-low dorsal (VD) gradients, Pax6, Foxg1, and Ngn2, were relatively unaffected in mutants (Fig. $3 A-C$ ). Additional section and wholemount studies indicated that mutant embryos invariably induce
Lhx2 and Emx2 but fail to upregulate and establish their DV gradients between E9.5 and E11.5, the period when intracortical gradients become detectable (data not shown). Thus, RP cells regulate dorsal cortical patterning in a selective manner, which includes upregulation of Tgif, Lhx2, and Emx2 and establishment of their DV gradients. The presence of dorsal cortical patterning defects by E10.5 (Fig. 2 E) (data not shown) indicates that initial RPdependent cortical patterning does not depend on the tCPe, whose definitive differentiation ensues later (by E11.5) (Currle et al., 2005).

\section{$\mathrm{RP}$ ablation causes reduction and}

flattening of the Bmp activity gradient Although steady-state levels of Bmp and Msx1 (msh homeobox homolog 1) mRNAs are reduced after $\mathrm{RP}$ ablation (Currle et al., 2005), direct studies of Bmp activity have been lacking. Indeed, graded Bmp activity has been presumed in the developing telencephalon based on precedent in other experimental systems but has not been directly demonstrated. Like other morphogens, TGF $\beta$ family signals, which include Bmps, are transduced in a pathway that appears to be strictly linear (Ashe and Briscoe, 2006). Linear TGF $\beta$ signal transduction is accomplished via the phosphorylation of Smad proteins and their subsequent translocation to the nucleus (Feng and Derynck, 2005). Because of its function as a direct and continuous transducer of extracellular TGF $\beta$ concentration with a short timescale (Bourillot et al., 2002), nuclear pSmad (or pMad in Drosophila) is a widely accepted integrative readout of Bmp signaling. In vertebrates, Bmp signals are specifically transduced via phosphorylation of Smad1, Smad5, and Smad8 (Feng and Derynck, 2005). A commercially available pSmad1/5/8 antibody (Chemicon) demonstrated appropriate specificity in tissue sections (Fig. 4) and in cultured E12.5 CD1 cortical cells treated with and without Bmp4 (for additional details regarding specificity, see Materials and Methods).

Studies of the E10.5 telencephalon revealed two distinct patterns of $\mathrm{pSmad} 1 / 5 / 8$ immunoreactivity (Fig. 4A). First, signal was particularly bright in many, but not all, cells lining the ventricles ( $\mathrm{M}$ phase cells). This pattern occurred throughout the telencephalon and lacked any obvious spatial gradient within the dorsal telencephalon (Fig. 4D). Second, within interphase cells of the dorsal telencephalon, pSmad signal was selectively nuclear and displayed a smooth DV gradient (Fig. $4 A-C)$. Interestingly, pSmad immunoreactivity was also relatively high in ventricular lining and interphase cells of the ventral 
telencephalon (Fig. 4A,B). Similar findings were observed in multiple control embryos at E12.5 (data not shown).

Within the dorsal telencephalon of RP ablated embryos, $\mathrm{pSmad}$ interphase and $\mathrm{M}$ phase cell labeling were markedly diminished (Fig. 4B-D). Within interphase cells, overall signal intensity was reduced by $>40 \%(42.5 \%)$, with a greater reduction medially ( $48.6 \%$ over the medial $0.2 \mathrm{~mm}$ ) than laterally $(34.8 \%$ over the lateral 0.2 $\mathrm{mm})$. This resulted in a flattening of the DV gradient in mutants relative to controls (Fig. 4C) (linear curve fit slopes, -0.018 gray value units/ $\mu \mathrm{m}$ in mutants, -0.048 units/ $\mu \mathrm{m}$ in controls). Likewise, average $\mathrm{M}$ phase cell intensity was markedly reduced in mutants $(47.4 \%$ reduction medially, $46.1 \%$ reduction laterally). Unlike the interphase cells, no spatial gradient in average $M$ phase signal intensity was detected within the dorsal telencephalon at E10.5 (Fig. $4 D)(p=0.951$, control medial vs lateral; $p=0.763$, mutant medial vs lateral). Although expression and activity of Smads and other Bmp pathway components could be altered after RP ablation, the pSmad data are consistent with the reduced dorsal midline Bmp production (Bmp4, Bmp6, and Bmp7) seen in RP ablated mutants (Currle et al., 2005). Importantly, these data also provide primary evidence for a true Bmp activity gradient in the normal dorsal telencephalon and its dependence on an intact RP.

\section{Exogenous Bmp4 selectively rescues RP-dependent midline patterning in explants}

To determine whether Bmp signals alone could replace an intact $\mathrm{RP}$, we bathed dorsal forebrain explants from E10.5 RP ablated embryos in exogenous Bmp4 or BSA and then quantified mRNA levels by qRT-PCR. The four downregulated midline/HPE genes (Msxl, Ttr, Lmxla, and Tgif) and the two genes unaffected or increased after RP ablation (Lhx5 and Zic2) were assayed. Because of developmental, phenotypic, and experimental variability, baseline expression levels in control explants varied significantly (Fig. 5A). Nonetheless, statistically significant rescue was achieved for Lmxla (Fig. 5A). In addition, trends toward upregulation in Bmp4-treated explants were seen for Msxl and Ttr, whereas Tgif levels remained relatively unchanged. Exogenous Bmp4 had no apparent effect on Lhx5 or Zic2 levels.

In addition to the aforementioned variability, rescues at the midline were likely to be masked by qRT-PCR assays on whole explants. We therefore performed identical explant cultures and assayed for tCPe, the most dorsal and most distinctive midline cell fate, by whole-mount ISH. Although none of the four mutant explants treated with BSA demonstrated Ttr rescue, six of the nine explants treated with Bmp4 demonstrated significant midline Ttr expression (Fig. 5B). Post hoc sectioning revealed Ttr expression within a thin (one to two cell layers thick) epithelium at the ventricular surface of all six Ttr-expressing explants. Remarkably, in two explants, Ttr rescue occurred in an extended simple epithelium that resembled normal tCPe (Fig. 5B, inset).
These findings suggest that Bmp4 was sufficient to rescue not only tCPe gene expression but also tCPe morphogenesis.

\section{Exogenous Bmp4 selectively upregulates RP-dependent midline genes in dissociated cells}

To further test how well Bmp4 could recapitulate RP-dependent selectivity in midline gene regulation, we quantified the same battery of genes in dissociated dorsal telencephalic cells cultured with Bmp4. By dissociating cells, and thereby homogenizing variations normally found within intact tissues, embryo and explant variation could be better controlled and the potential primacy of extracellular Bmp concentration tested more directly. This test of selectivity was particularly stringent, because cells from E12.5 embryos were used, a stage well past the midline inductive period in vivo.

Nonetheless, exogenous Bmp4 significantly upregulated two of the four RP-dependent genes (Msxl and Tgif) in a consistent manner across three CD1 cultures and two B6 cultures in two different base media (Fig. 5C) (supplemental Fig. 2, available at www.jneurosci.org as supplemental material). Ttr and Lmxla also displayed upregulatory trends in all dose-response curves, occasionally reaching statistical significance (supplemental Fig. 2, available at www.jneurosci.org as supplemental material). In contrast, the Lhx5 and Zic2 dose-response curves were consistently flat and failed to reach statistical significance in any culture.

\section{The embryonic mouse model accurately predicts the human MIH HPE phenotype}

Our mouse studies led to three specific predictions about neuroanatomical defects in human MIH HPE patients. First, surviving patients should have markedly reduced to absent tCPe (Currle et 
A

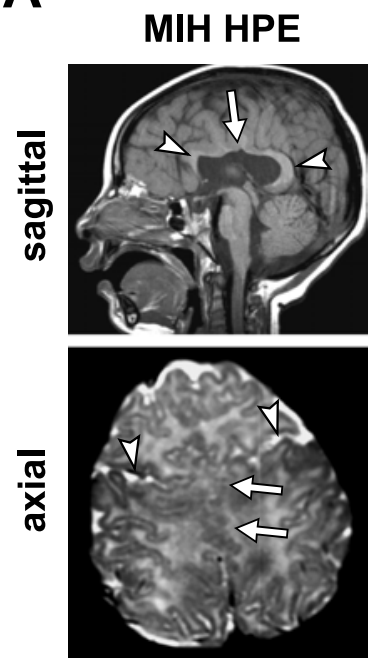

B
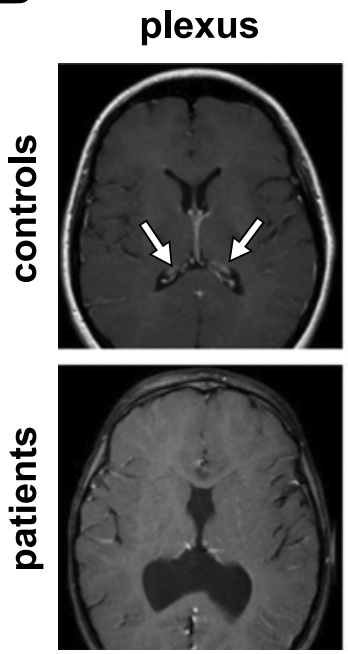

hippocampus
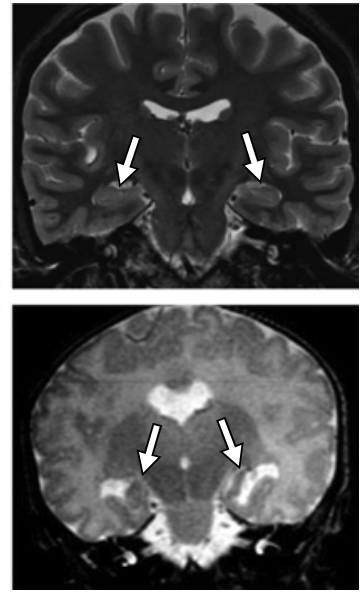

Figure 6. MIH HPE patient defects predicted by the mouse RP ablation phenotype. A, T1-weighted sagittal and T2-weighted axial MRI scans. The middle interhemispheric phenotype is demonstrated on the sagittal image by apparent absence of the midbody of the corpus callosum (arrow), whereas the rostrum and genu are better preserved (arrowheads). The axial scan demonstrates abnormal midline gray matter in central hemispheric regions (arrows) and the characteristic anterior displacement of Sylvian fissures (arrowheads). B, Choroid plexus and hippocampal defects; T1-weighted axial and T2-weighted coronal MRI images of patients shown in $\boldsymbol{A}$. Choroid plexus, which enhances with contrast (arrows in top left panel), is undetectable in the contrast-enhanced scan of the MIH HPE patient. The coronal image displays hippocampi that are small and dysplastic compared with control (arrows in right panels). All 23 cases reviewed demonstrated marked tCPe deficiency, and 7 of 11 cases with adequate images exhibited reduced hippocampal size.

\section{Normal development}

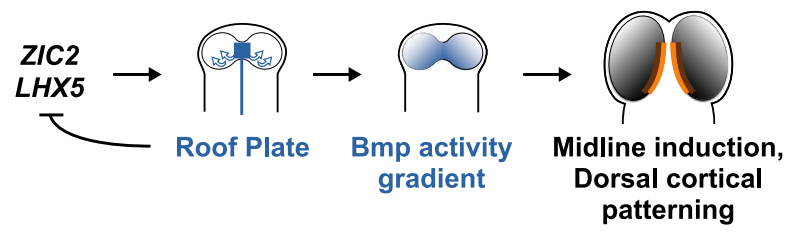

Pathways to MIH HPE

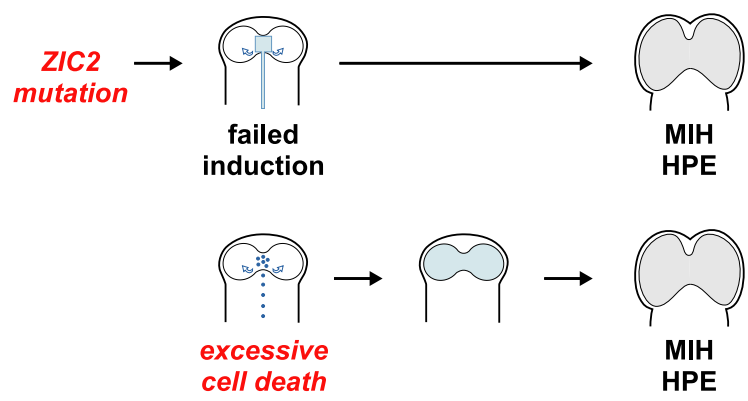

Figure 7. The "central" RP-Bmp pathway in dorsal telencephalic patterning and MIH HPE. A, Normal development. Zic2 induces the RP, which produces Bmps that generate a Bmp activity gradient in the dorsal telencephalon. This activity gradient then directs dorsal midline induction (tCPe and cortical hem in orange and brown, respectively) and dorsal cortical patterning. LHX5 also acts upstream of the RP, and the RP exerts negative feedback that restricts Zic2 and Lhx5 expression to the midline. B, Pathways to MIH HPE. Two independent pathways give rise to RP deficits that ultimately lead to MIH HPE. In the first pathway, the RP deficit results from failed induction as a result of reduced Zic2 function. In the second (Zic2-independent) pathway, RP dysfunction arises from excessive $\mathrm{RP}$ cell death, which leads to reduced Bmp signaling in the dorsal telencephalon. In addition to ZIC2 mutations, candidate inducers of MIH HPE include LHX5 mutations, factors that exacerbate RP cell death (including increased Bmp signaling) and mutations that decrease Bmp signaling. For additional details, see Discussion. al., 2005). Second, because Wnt3a, Lhx2, and $\mathrm{Em} \times 2$ are positive regulators of dorsal cortical (hippocampal) precursor proliferation (Porter et al., 1997; Lee et al., 2000b; Tole et al., 2000), their reduced expression should lead to reduced hippocampal size. Third, because mouse RP ablation defects are more severe toward the dorsal midline, tCPe should be more significantly affected than the hippocampus. Although ACTBCre;Gdf7DTA embryos rarely survive past E14.5, human MIH HPE patients can survive postnatally. Hippocampal and CPe reductions have been noted in at least two and nine MIH HPE cases, respectively (Barkovich and Quint, 1993; Marcorelles et al., 2002), but their prevalence and association with the disorder remained uncertain.

We therefore examined the hippocampus and $\mathrm{tCPe}$ in magnetic resonance imaging (MRI) scans from a cohort of $23 \mathrm{MIH}$ HPE patients (Fig. 6A). Despite the uneven quality of imaging studies, tCPe appeared to be either totally absent or significantly reduced in all 23 patients (Fig. $6 B$ ). Eleven patients had coronal images that were adequate to assess hippocampal size; among these, seven showed small, and often dysplastic, hippocampi (Fig. 6B). Thus, marked reduction in tCPe volume and small hippocampi, with the tCPe phenotype appearing more severe, are characteristic features of human MIH HPE, as predicted by the mouse model.

\section{Discussion}

Our studies define multiple developmental processes in the dorsal telencephalon that depend on the RP (Fig. 7). In addition to tCPe induction (Currle et al., 2005), the RP is required for normal cortical hem formation and dorsal cortical patterning. The lack of multiple hem markers after ablation (Msx1, Lmx1a, Wnt2b, and Wnt3a), which belong to different gene classes (transcription factors and signaling proteins), suggests that the RP is needed to induce cortical hem fate. By regulating dorsal cortical patterning, including Emx2 expression, the RP is also implicated in cortical areal map formation (Bishop et al., 2000; Mallamaci et al., 2000; Fukuchi-Shimogori and Grove, 2003; Hamasaki et al., 2004).

These RP patterning functions are mediated via a Bmp activity gradient in the dorsal telencephalon (Fig. 4), which depends on the RP in a primarily cell-nonautonomous manner. Interestingly, $\mathrm{RP}$ ablation does not result in uniform gradient reduction (i.e., a similar gradient profile starting at a lower initial Bmp signaling level), which would be predicted from a model based exclusively on dorsal midline Bmp sources. Instead, RP ablation resulted in both flattening and reduction of the gradient. This suggests that Bmp signaling in the dorsal telencephalon, particularly in its ventrolateral domain, is also regulated by nondorsal sources of Bmps or other factors that promote nuclear pSmad accumulation. The significant nuclear pSmad levels seen in interphase cells of the ventral telencephalon (Fig. 4) (data not shown) would be consistent with a nondorsal Bmp source, such as the ventral midline (Solloway and Robertson, 1999; Lee et al., 2000a). RP ablation also affects pSmad staining in cells at the ventricular surface (Fig. 
4), although the mechanisms accounting for accentuated staining of normal $\mathrm{M}$ phase cells remain uncertain. This pattern could simply reflect loss of nuclear compartmentalization during $M$ phase. However, accumulation during $\mathrm{M}$ phase would also be consistent with the presence of Bmp2/4 at the cortical ventricular surface ( $\mathrm{Li}$ et al., 1998), which raises possibilities such as Bmp production/release at the ventricular surface (Li et al., 1998) or into the CSF.

Our studies also firmly establish a primary role for Bmps in $\mathrm{RP}$-dependent tCPe induction. Although Wnts undoubtedly contribute to RP-dependent patterning (Fig. 2A), the rescue studies provide the first evidence that Bmps alone are sufficient to induce tCPe. This evidence for sufficiency complements the known requirements for RP (Currle et al., 2005) and the BmpRIa receptor (Hebert et al., 2002) in this process. The rescue of both tCPe gene expression and morphogenesis appears to parallel Bmp [dpp (decapentaplegic)] functions in patterning and epithelial morphogenesis in the fly wing, which are dissociable (Gibson and Perrimon, 2005; Shen and Dahmann, 2005). Bmp activity is continuously graded across the tCPe anlagen (Fig. 4), suggesting that the irreversible tCPe cell fate decision occurs above a critical Bmp activity threshold. This stands in contrast to the DV gradients within cortical neuroepithelium, which have a more linear correlation with Bmp activity in normal and RP ablated embryos.

In addition to their roles in normal development, our studies directly implicate the RP and the RP-dependent Bmp activity gradient in MIH HPE induction and pathogenesis. As discussed previously, the RP-Bmp pathway is likely to be secondarily involved in classical HPE as well and may have a more primary role in classical HPE cases in which the neuropathology is most severe in the middle interhemispheric region (Takahashi et al., 2003). The embryo and dissociated culture studies suggest that Tgif, which is genetically associated with human HPE (Gripp et al., 2000), is regulated by the RP-Bmp pathway. However, the specific role of Tgif in MIH HPE remains unclear, because total Tgif loss-of-function in mice is insufficient to cause defective midline induction or HPE (Shen and Walsh, 2005).

In contrast, our studies clarify the relationship of Zic2 to the RP and MIH HPE. ZIC2 is the only human gene linked specifically to the MIH variant (Brown et al., 2001), and reduced Zic2 expression in mice, which is normally highest at the dorsal midline (Fig. 2E), causes delayed neurulation, failed RP induction, and dorsal HPE (Nagai et al., 2000). Thus, Zic2 is upstream of RP induction. Our studies indicate that RP failure alone (via cellular ablation) is sufficient to generate MIH HPE. Thus, other hypothetical Zic2-dependent but RP-independent pathways (which should be intact after RP ablation as a result of maintained Zic2 expression) are unnecessary to explain the malformation phenotype. Collectively, these studies strongly implicate a Zic2-RP pathway in MIH HPE induction and pathogenesis (Fig. 7). Although the RP depends on Zic2, the converse is not the case, because Zic2 levels remained high after RP ablation and were unaltered by exogenous Bmp4 in explants and dissociated cells. These findings argue against any positive feedback from the RP back to Zic2. However, Zic2 expression in vivo was more expansive after RP ablation (Fig. 2E), suggesting RP-dependent negative feedback on Zic2 that is not mediated by Bmp4 alone.

Although RP failure can account for ZIC2-associated MIH HPE, most human ZIC2 mutations cause more severe classical HPE phenotypes. Notably, the ZIC2 mutations associated with classical HPE predict severe or complete loss-of-function, whereas the mutation linked to MIH HPE is a presumed hypomorph (12 amino acid in-frame deletion) (Brown et al., 2001). In addition, Zic2 knockdown in mice ( $\sim 20 \%$ of normal), rather than complete Zic2 loss, is sufficient to induce RP failure and dorsal HPE (Nagai et al., 2000). This suggests that the RP is particularly sensitive to ZIC2 deficiency - i.e., partially reduced ZIC2 function leads to RP failure (and MIH HPE), whereas severe ZIC2 loss causes midline defects that extend beyond the RP into the rostral and ventral forebrain (classical HPE). Such extension could be directly related to Zic2 expression in the ventral midline (Fig. 2E) (Nagai et al., 1997; Hayhurst and McConnell, 2003), a region well known for its causal role in classical HPE.

Reduced Zic2 function leads to failed RP induction rather than excessive RP cell death (Nagai et al., 2000), yet RP failure from either mechanism can induce MIH HPE. Thus, increased $\mathrm{RP}$ cell death represents a second, Zic2-independent mechanism that can give rise to the malformation phenotype (Fig. 7). Interestingly, manipulations that increase Bmp signaling are known to increase RP cell death. Physiologic RP cell death is regulated by Bmp activity (Furuta et al., 1997; Solloway and Robertson, 1999), and increased Bmp signaling leads to excessive apoptosis in forebrain patterning centers, including the RP (Golden et al., 1999; Anderson et al., 2002; Ohkubo et al., 2002). Thus, although globally increased Bmp activity has the potential to cause classical human HPE (via ventral Shh suppression) (Golden et al., 1999; Bachiller et al., 2000; Anderson et al., 2002; Ohkubo et al., 2002), focally increased Bmp signaling at the dorsal midline could lead to excessive RP cell death and human MIH HPE. Conversely, mutations that block or decrease Bmp signaling, thus mimicking the reduced Bmp activity gradient seen after RP ablation, could also conceivably be involved.

LHX5 also emerges as a candidate MIH HPE gene based on our work and inspection of the mouse Lhx 5 null phenotype (Zhao et al., 1999). Lhx5 expression ensues by E8.5 in the RP (Fig. 2C) (data not shown), and the Lhx 5 expression changes observed in the tissue, explant, and dissociated culture studies closely parallel those of Zic2, suggesting that Lhx 5 also acts upstream of the $\mathrm{RP}$ and is subject to RP-mediated negative feedback. Importantly, the Lhx5 null mouse appears to display many cardinal features of the RP ablation phenotype: (1) morphologic absence of tCPe, (2) loss of tCPe and hem markers (Bmp7 and Wnt5a), and (3) extension of cortical markers to the midline [Lhx2, Emx2, and Otx2 (orthodenticle homolog 2)] (Zhao et al., 1999). Although it is uncertain whether Lhx5 mutants have MIH HPE, these observations suggest that $\mathrm{Lhx} 5$ is essential for RPdependent Bmp signaling.

\section{References}

Anderson RM, Lawrence AR, Stottmann RW, Bachiller D, Klingensmith J (2002) Chordin and noggin promote organizing centers of forebrain development in the mouse. Development 129:4975-4987.

Ashe HL, Briscoe J (2006) The interpretation of morphogen gradients. Development 133:385-394.

Bachiller D, Klingensmith J, Kemp C, Belo JA, Anderson RM, May SR, McMahon JA, McMahon AP, Harland RM, Rossant J, De Robertis EM (2000) The organizer factors Chordin and Noggin are required for mouse forebrain development. Nature 403:658-661.

Barkovich AJ, Quint DJ (1993) Middle interhemispheric fusion: an unusual variant of holoprosencephaly. Am J Neuroradiol 14:431-440.

Bishop KM, Goudreau G, O'Leary DD (2000) Regulation of area identity in the mammalian neocortex by Emx2 and Pax6. Science 288:344-349.

Bourillot PY, Garrett N, Gurdon JB (2002) A changing morphogen gradient is interpreted by continuous transduction flow. Development 129:2167-2180.

Brown LY, Odent S, David V, Blayau M, Dubourg C, Apacik C, Delgado MA, Hall BD, Reynolds JF, Sommer A, Wieczorek D, Brown SA, Muenke M (2001) Holoprosencephaly due to mutations in ZIC2: alanine tract ex- 
pansion mutations may be caused by parental somatic recombination. Hum Mol Genet 10:791-796.

Burrows RC, Wancio D, Levitt P, Lillien L (1997) Response diversity and the timing of progenitor cell maturation are regulated by developmental changes in EGFR expression in the cortex. Neuron 19:251-267.

Chizhikov VV, Lindgren AG, Currle DS, Rose MF, Monuki ES, Millen KJ (2006) The roof plate regulates cerebellar cell-type specification and proliferation. Development, in press.

Currle DS, Cheng X, Hsu CM, Monuki ES (2005) Direct and indirect roles of CNS dorsal midline cells in choroid plexus epithelia formation. Development 132:3549-3559.

Feng XH, Derynck R (2005) Specificity and versatility in tgf-beta signaling through Smads. Annu Rev Cell Dev Biol 21:659-693.

Flanagan LA, Rebaza LM, Derzic S, Schwartz PH, Monuki ES (2006) Regulation of human neural precursor cells by laminin and integrins. J Neurosci Res 83:845-856.

Fukuchi-Shimogori T, Grove EA (2003) Emx2 patterns the neocortex by regulating FGF positional signaling. Nat Neurosci 6:825-831.

Furuta Y, Piston DW, Hogan BL (1997) Bone morphogenetic proteins (BMPs) as regulators of dorsal forebrain development. Development 124:2203-2212.

Gibson MC, Perrimon N (2005) Extrusion and death of DPP/BMPcompromised epithelial cells in the developing Drosophila wing. Science 307:1785-1789.

Golden JA, Bracilovic A, McFadden KA, Beesley JS, Rubenstein JL, Grinspan JB (1999) Ectopic bone morphogenetic proteins 5 and 4 in the chicken forebrain lead to cyclopia and holoprosencephaly. Proc Natl Acad Sci USA 96:2439-2444.

Gripp KW, Wotton D, Edwards MC, Roessler E, Ades L, Meinecke P, Richieri-Costa A, Zackai EH, Massague J, Muenke M, Elledge SJ (2000) Mutations in TGIF cause holoprosencephaly and link NODAL signalling to human neural axis determination. Nat Genet 25:205-208.

Grove EA, Tole S, Limon J, Yip L, Ragsdale CW (1998) The hem of the embryonic cerebral cortex is defined by the expression of multiple Wnt genes and is compromised in Gli3-deficient mice. Development $125: 2315-2325$.

Hamasaki T, Leingartner A, Ringstedt T, O’Leary DD (2004) EMX2 regulates sizes and positioning of the primary sensory and motor areas in neocortex by direct specification of cortical progenitors. Neuron 43:359-372.

Hayhurst M, McConnell SK (2003) Mouse models of holoprosencephaly. Curr Opin Neurol 16:135-141.

Hebert JM, Mishina Y, McConnell SK (2002) BMP signaling is required locally to pattern the dorsal telencephalic midline. Neuron 35:1029-1041.

Hebert JM, Hayhurst M, Marks ME, Kulessa H, Hogan BL, McConnell SK (2003) BMP ligands act redundantly to pattern the dorsal telencephalic midline. Genesis 35:214-219.

Lee KJ, Jessell TM (1999) The specification of dorsal cell fates in the vertebrate central nervous system. Annu Rev Neurosci 22:261-294.

Lee KJ, Dietrich P, Jessell TM (2000a) Genetic ablation reveals that the roof plate is essential for dorsal interneuron specification. Nature 403:734-740.

Lee SM, Tole S, Grove E, McMahon AP (2000b) A local Wnt-3a signal is required for development of the mammalian hippocampus. Development 127:457-467.

Li W, Cogswell CA, LoTurco JJ (1998) Neuronal differentiation of precursors in the neocortical ventricular zone is triggered by BMP. J Neurosci $18: 8853-8862$.

Liem Jr KF, Tremml G, Jessell TM (1997) A role for the roof plate and its resident TGFbeta-related proteins in neuronal patterning in the dorsal spinal cord. Cell 91:127-138.

Mallamaci A, Muzio L, Chan CH, Parnavelas J, Boncinelli E (2000) Area identity shifts in the early cerebral cortex of Emx2-/- mutant mice. Nat Neurosci 3:679-686.

Marcorelles P, Loget P, Fallet-Bianco C, Roume J, Encha-Razavi F, Delezoide AL (2002) Unusual variant of holoprosencephaly in monosomy 13q. Pediatr Dev Pathol 5:170-178.

Millonig JH, Millen KJ, Hatten ME (2000) The mouse Dreher gene Lmxla controls formation of the roof plate in the vertebrate CNS. Nature 403:764-769.

Ming JE, Golden JA (2004) Midline patterning defects. In: Developmental neuropathology (Golden JA, Harding B, eds), p 386. Basel: International Society for Neuropathology.

Monuki ES, Walsh CA (2001) Mechanisms of cerebral cortical patterning in mice and humans. Nat Neurosci [Suppl] 4:1199-1206.

Monuki ES, Porter FD, Walsh CA (2001) Patterning of the dorsal telencephalon and cerebral cortex by a roof plate-Lhx2 pathway. Neuron 32:591-604.

Muenke M, Beachy PA (2000) Genetics of ventral forebrain development and holoprosencephaly. Curr Opin Genet Dev 10:262-269.

Nagai T, Aruga J, Takada S, Gunther T, Sporle R, Schughart K, Mikoshiba K (1997) The expression of the mouse Zic1, Zic2, and Zic3 gene suggests an essential role for Zic genes in body pattern formation. Dev Biol 182:299-313.

Nagai T, Aruga J, Minowa O, Sugimoto T, Ohno Y, Noda T, Mikoshiba K (2000) Zic2 regulates the kinetics of neurulation. Proc Natl Acad Sci USA 97:1618-1623.

Norman MG (1995) Congenital malformations of the brain: pathologic, embryologic, clinical, radiologic, and genetic aspects. New York: Oxford UP.

Ohkubo Y, Chiang C, Rubenstein JL (2002) Coordinate regulation and synergistic actions of BMP4, SHH and FGF8 in the rostral prosencephalon regulate morphogenesis of the telencephalic and optic vesicles. Neuroscience 111:1-17.

Porter FD, Drago J, Xu Y, Cheema SS, Wassif C, Huang SP, Lee E, Grinberg A, Massalas JS, Bodine D, Alt F, Westphal H (1997) Lhx2, a LIM homeobox gene, is required for eye, forebrain, and definitive erythrocyte development. Development 124:2935-2944.

Qian X, Goderie SK, Shen Q, Stern JH, Temple S (1998) Intrinsic programs of patterned cell lineages in isolated vertebrate CNS ventricular zone cells. Development 125:3143-3152.

Shen J, Dahmann C (2005) Extrusion of cells with inappropriate Dpp signaling from Drosophila wing disc epithelia. Science 307:1789-1790.

Shen J, Walsh CA (2005) Targeted disruption of Tgif, the mouse ortholog of a human holoprosencephaly gene, does not result in holoprosencephaly in mice. Mol Cell Biol 25:3639-3647.

Simon EM, Hevner RF, Pinter JD, Clegg NJ, Delgado M, Kinsman SL, Hahn JS, Barkovich AJ (2002) The middle interhemispheric variant of holoprosencephaly. Am J Neuroradiol 23:151-156.

Solloway MJ, Robertson EJ (1999) Early embryonic lethality in Bmp5;Bmp7 double mutant mice suggests functional redundancy within the $60 \mathrm{~A}$ subgroup. Development 126:1753-1768.

Takahashi T, Kinsman S, Makris N, Grant E, Haselgrove C, McInerney S, Kennedy DN, Fredrickson K, Mori S, Caviness VS (2003) Semilobar holoprosencephaly with midline "seam": a topologic and morphogenetic model based upon MRI analysis. Cereb Cortex 13:1299-1312.

Tole S, Goudreau G, Assimacopoulos S, Grove EA (2000) Emx2 is required for growth of the hippocampus but not for hippocampal field specification. J Neurosci 20:2618-2625.

Zhao GQ (2003) Consequences of knocking out BMP signaling in the mouse. Genesis 35:43-56.

Zhao Y, Sheng HZ, Amini R, Grinberg A, Lee E, Huang S, Taira M, Westphal H (1999) Control of hippocampal morphogenesis and neuronal differentiation by the LIM homeobox gene Lhx5. Science 284:1155-1158. 